Case Report

\title{
Nutcracker Cuboid Fracture: A Case Report and Review
}

\author{
Alan Lucerna $\left(\mathbb{D},{ }^{1}\right.$ James Espinosa $(D),{ }^{1}$ Nicholas Butler, ${ }^{2}$ \\ Ashley Wenke, ${ }^{3}$ and Nicole Caltabiano ${ }^{3}$ \\ ${ }^{1}$ Department of Emergency Medicine, Rowan University SOM and Jefferson Health, Stratford, NJ, USA \\ ${ }^{2}$ Department of Podiatric Medicine, Jefferson Health, Stratford, NJ, USA \\ ${ }^{3}$ Rowan University SOM, Stratford, NJ, USA \\ Correspondence should be addressed to Alan Lucerna; lucernaa@gmail.com
}

Received 26 November 2017; Accepted 3 January 2018; Published 3 April 2018

Academic Editor: Aristomenis K. Exadaktylos

Copyright (C) 2018 Alan Lucerna et al. This is an open access article distributed under the Creative Commons Attribution License, which permits unrestricted use, distribution, and reproduction in any medium, provided the original work is properly cited.

\begin{abstract}
Here we report the case of a 20 -year-old female restrained driver who presented to the emergency department (ED) after a motor vehicle accident. She sustained an isolated fracture of her left cuboid, consistent with a nutcracker cuboid fracture. A cuboid fracture is considered rare. It is even more uncommon for a cuboid fracture to occur in isolation, without other associated injuries to the foot. We discuss the mechanism, relevant anatomy, diagnosis, and principles of treatment of the nutcracker cuboid fracture.
\end{abstract}

\section{Introduction}

The anatomy of the cuboid is complex, with six articular surfaces involvement in all of the intrinsic movements of the midfoot and hindfoot [1]. Due to this anatomy, a cuboid fracture is considered rare. It is even more uncommon for a cuboid fracture to occur in isolation, without other associated injuries to the foot [2]. We report the case of a 20 -year-old female restrained driver who presented to the emergency department (ED) after a motor vehicle accident.

\section{Case Report}

A 20-year-old female restrained driver presented to the emergency department (ED) after motor vehicle accident. She complained of left clavicular and left foot pain. A left clavicular fracture was found on exam and on the imaging studies. An X-ray of the left foot showed a commuted fracture of the cuboid bone with mildly displaced fragments, as well as moderate soft tissue edema (Figure 1). Clinical exam did not show evidence of other foot or leg injuries. The rest of her exam was unremarkable. An orthopedic consult was obtained in the emergency department. A posterior fiberglass splint was recommended as well as non-weight bearing on the affected foot. The patient was to follow up on an outpatient basis with orthopedic surgery. The fracture was consistent with a nutcracker cuboid fracture.

\section{Discussion}

3.1. Incidence of Cuboid Fractures. A cuboid fracture is considered rare. It is even more uncommon for a cuboid fracture to occur in isolation, without other associated injuries to the foot [2]. This is said to be because of a relatively protected position in the midfoot [3].

3.2. Classification. According to Smith et al., who performed a large retrospective study of cuboid fractures, there is no current widely accepted classification for cuboid fractures and there are no long-term outcome studies [3].

3.3. Anatomy. The anatomy of the cuboid is complex, with six articular surfaces' involvement in all of the intrinsic movements of the midfoot and hindfoot [1]. The cuboid constitutes part of the lateral longitudinal arch of the foot [4]. It is the only bony structural support for the lateral column of the midfoot [5]. Of note, the tendon of the peroneus longus courses in a groove on the inferior surface 


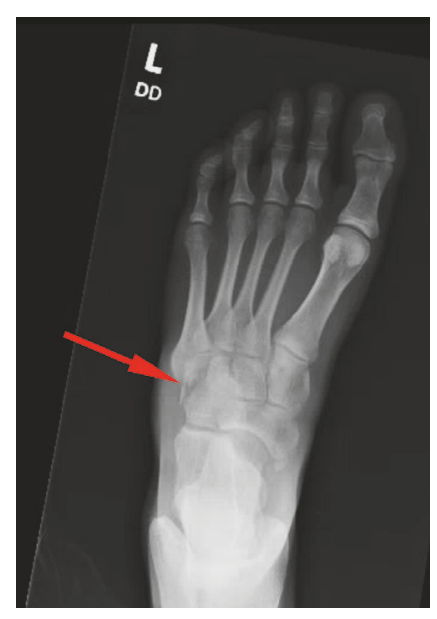

(a)

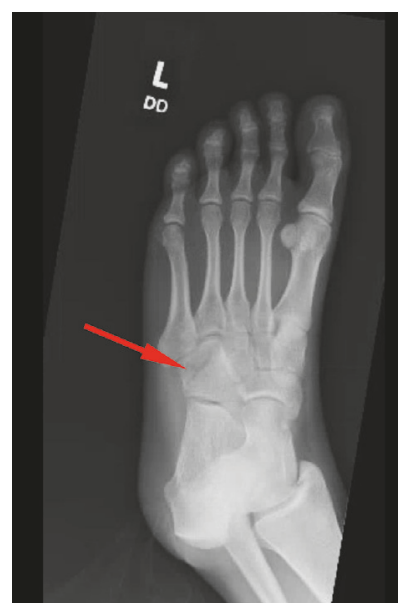

(b)

FIGURE 1: An X-ray of the left foot showed a commuted fracture of the cuboid bone with mildly displaced fragments, as well as moderate soft tissue edema (red arrows).

of the cuboid bone [4]. The plantar surface of the cuboid has attachments for the short and long plantar ligaments [2]. Because of these important anatomic elements, "any disturbance of the articular surfaces of the cuboid can lead to a profound disruption of the movement and biomechanics of the midfoot" [2]. Loss of length of the lateral column due to a cuboid fracture can result in abduction of the forefoot with a planus deformity. There can be compensatory eversion of the hindfoot [2].

3.4. Nutcracker Mechanism and Fracture. Isolated fractures of the cuboid, as in the case presented, are rare. It is more common to find cuboid fractures from a crush injury, in association with other foot fractures and injuries $[1,3,4]$. Hermel and Gershon-Cohen described a mechanism that can result in an isolated cuboid fracture, in which forced abduction of the forefoot, generally in combination with an axial load, can compress the cuboid between the bases of the 4th and 5th metatarsals and the calcaneus [6]. Plantar flexion of the foot may be involved at the time of injury (Gaines). The authors likened this compression to a nutcracker effect and noted that this mechanism can result in a "nutcracker cuboid fracture" [3, 6-8]. It is likely that the patient described had just such a force (axial load with abduction) from the motor vehicle accident. Nutcracker cuboid fractures have been described in ballet dancers, likely due to repetitive axial loading of the foot [9]. Children have been described with nutcracker cuboid injuries associated with horseback riding [10]. Hsu et al. note that "little has been published on the frequency, diagnosis or treatment of the nutcracker fracture in the pediatric population." Nutcracker cuboid injuries in children can be difficult to diagnose [11].

3.5. Diagnosis. The diagnosis may be difficult to make and can be missed on the initial evaluation [5].

Imaging includes X-rays of the foot. An oblique view may help to define the calcaneal-cuboid and metatarsal-cuboid relationship [7]. Computerized tomography (CT) imaging may be helpful when the diagnosis is unclear [5].

3.6. Treatment. Little high-quality evidence can be found on the best treatment for navicular-cuboid fractures. The treatments described in the literature include such options as immobilization with casting, external fixation, and open reduction internal fixation with or without bone grafting. Midtarsal fusion has been described. Yu et al. note that "the indications and the best method of surgical treatment have not been established due the rarity of the fracture and the paucity of literature" [5].

Koch makes a similar point. "Due to the limited number of reported cases of nutcracker fractures, the best method of treatment has not been determined" [12]. Ohmori et al. reported a "new treatment plan" for an isolated nutcracker injury-arthroscopic elevation of depressed bone fragments and the use of a bone biopsy needle to fill in the large defect with artificial bone [13]. Nondisplaced fractures may be treated with a short leg cast and non-weight-bearing status [14]. Comminuted fractures will more likely need an operative procedure [14]. Smith et al. note that when a nutcracker cuboid fracture is associated with lateral column shortening, lengthening of the lateral column, open reduction internal fixation (ORIF), and bone grafting may be needed [3]. External fixation may have a role in some cases [8]. Yu et al. recommend open treatment for cuboid fractures when there is a one millimeter or more shortening of the lateral column [5].

3.7. Outcomes. As noted by Fenton et al., "there are no long term reports of outcomes following fractures of the cuboid" [2]. The major concerns with outcome include pain, loss of the lateral structural integrity of the foot, and decreased range of motion of the lateral tarsometatarsal joints [5]. 


\section{Conclusions}

Cuboid fractures are considered rare, even more so without other associated injuries to the foot. It is likely that the patient described had just such a force (axial load with abduction) from the motor vehicle accident. Little high-quality evidence can be found on the best treatment for navicular-cuboid fractures.

Nondisplaced fractures may be treated with a short leg cast and non-weight-bearing status. Comminuted fractures will more likely need an operative procedure like open reduction internal fixation (ORIF) and bone grafting as well as placement of external fixators. There are no long-term reports of outcomes following fractures of the cuboid. The major concerns with outcome include pain, loss of the lateral structural integrity of the foot, and decreased range of motion of the lateral tarsometatarsal joints.

\section{Conflicts of Interest}

The authors declare that they have no conflicts of interest.

\section{References}

[1] B. Sangeorzan and M. Swiontkowski, "Displaced fractures of the cuboid," The Journal of Bone \& Joint Surgery (British Volume), vol. 72-B, no. 3, pp. 376-378, 1990.

[2] P. Fenton, S. Al-Nammari, C. Blundell, and M. Davies, "The patterns of injury and management of cuboid fractures: a retrospective case series," The bone \& joint journal, vol. 98-B, no. 7, pp. 1003-1008, 2016.

[3] W. R. Smith, P. F. Stahel, T. Suzuki, and P. Gabrielle, Current Diagnosis \& Treatment in Orthopedics, Musculoskeletal Trauma Surgery, chapter 2, McGraw-Hill, New York, NY, USA, 5th edition, 2014.

[4] H. Jahn and K. G. Freund, "Isolated fractures of the cuboid bone: two case reports with review of the literature," The Journal of Foot Surgery, vol. 28, no. 6, pp. 512-515, 1989.

[5] G. Yu, T. Yu, Y. Yang, B. Li, F. Yuan, and J. Zhou, "Nutcracker fracture of the cuboid: management and results," Acta Orthopaedica Belgica, vol. 78, no. 2, pp. 216-219, 2012.

[6] M. B. Hermel and J. Gershon-Cohen, "The nutcracker fracture of the cuboid by indirect violence," Radiology, vol. 60, no. 6, pp. 850-854, 1953.

[7] R. B. Abu-Laban and N. G. Rose, "Ankle and Foot," in Rosen's Emergency Medicine: Concepts and Clinical Practice, J. A. Marx, R. S. Hockberger, and R. M. Walls, Eds., Philadelphia, Pa, USA, Elsevier Health Sciences, 2014.

[8] M. W. Chapman, R. M. Szabo, and R. A. Marder, Chapman's Orthopaedic Surgery, chapter 111, LWW, Philadelphia, Pa, USA, 2000.

[9] S. Carsen, B. J. Quinn, E. Beck, H. Southwick, and L. J. Micheli, " "Nutcracker Fracture" in a Ballet Dancer Performing in The Nutcracker," Journal of dance medicine \& science : official publication of the International Association for Dance Medicine \& Science, vol. 19, no. 3, pp. 124-127, 2015.

[10] D. Ceroni, V. De Rosa, G. De Coulon, and A. Kaelin, "Cuboid nutcracker fracture due to horseback riding in children: case series and review of the literature," Journal of Pediatric Orthopaedics, vol. 27, no. 5, pp. 557-561, 2007.
[11] J. Hsu, J. Chang, S. Wang, and S. Wu, “The Nutcracker Fracture of the Cuboid in Children: A Case Report," Foot \& Ankle International, vol. 25, no. 6, pp. 423-425, 2016.

[12] J. Koch, "Rahimi Nutcracker fractures of the cuboid," The Journal of Foot Surgery, vol. 30, no. 4, pp. 336-339, 1991.

[13] T. Ohmori, S. Katsuo, C. Sunayama et al., "A Case Report of Isolated Cuboid Nutcracker Fracture," Case Reports in Orthopedics, vol. 2016, Article ID 3264172, 5 pages, 2016.

[14] S. Gaines and D. A. Handel, "Foot Injuries," in Tintinallis Emergency Medicine: A Comprehensive Study Guide, J. E. Tintinalli, J. Stapczynski, O. Ma, D. M. Yealy, G. D. Meckler, and D. M. Cline, Eds., McGraw-Hill Education, New York, NY, USA, 2016. 


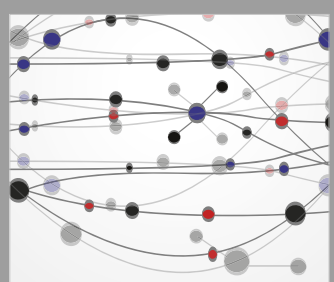

The Scientific World Journal
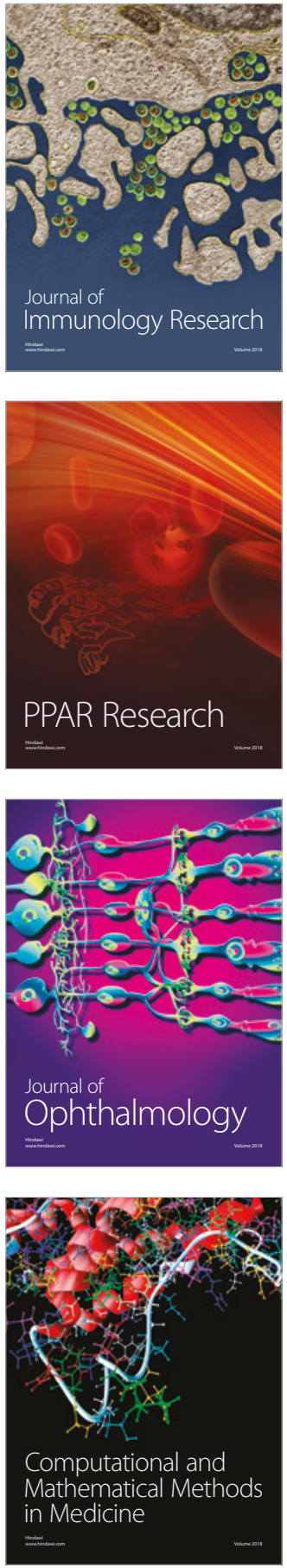

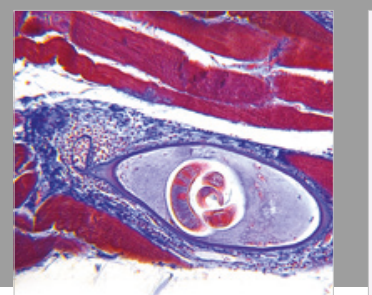

Gastroenterology Research and Practice



\section{Hindawi}

Submit your manuscripts at

www.hindawi.com
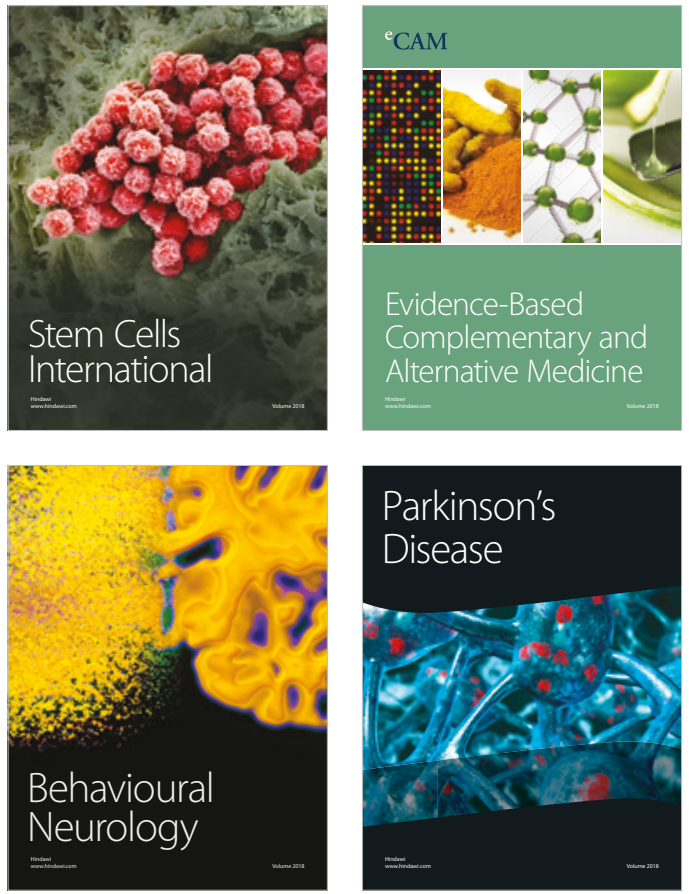

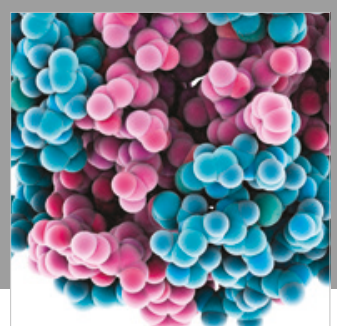

ournal of

Diabetes Research

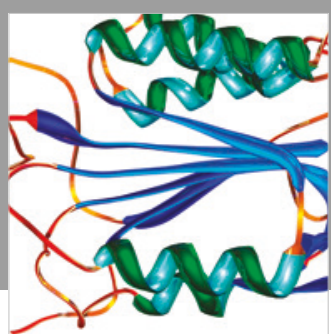

Disease Markers
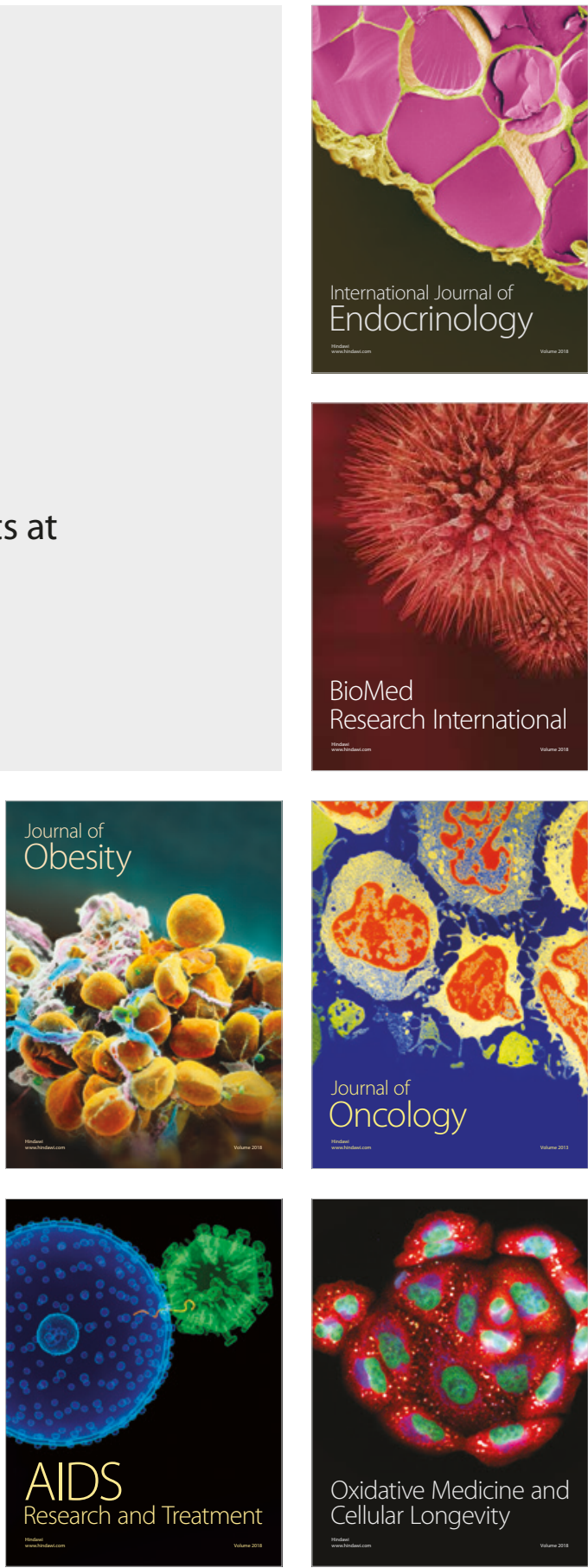